\title{
Variability in Antinutritional compounds in Hempseed meal of Italian and French varieties
}

\author{
Roberto Russo, Remo Reggiani \\ Istituto di Biologia e Biotecnologia Agraria, CNR, Milano, Italy \\ Email address: \\ russo@ibba.cnr.it(R. Russo), reggiani@ibba.cnr.it(R. Reggiani)
}

\section{To cite this article:}

Roberto Russo, Remo Reggiani, Variability in Antinutritional Compounds in Hempseed Meal of Italian and French Varieties. Plant. Vol. 1, No. 2, 2013, pp. 25-29. doi: 10.11648/j.plant.20130102.13

\begin{abstract}
The use of hempseed flours in the animal diets may be limited by the presence of antinutritive compounds. The content of phytic acid, condensed tannins, trypsin inhibitors, cyanogenic glycosides and saponins was evaluated in hempseed meal of three italian varieties (dioecious) and three french varieties (monoecious) of Cannabis sativa L. The analysis of variance showed significant differences among varieties for all the antinutritional compounds. The italian and french hemp groups resulted significantly different in the content of phytic acid, trypsin inhibitors and cyanogenic glycosides. The concentration of phytic acid in the hempseed flour deserves attention in both groups, while the content of cyanogenic glycosides deserves attention just in the french varieties, and condensed tannins, trypsin inhibitors and saponins are instead to acceptable levels. The french varieties presented less phytic acid than those italians $\left(-0.55 \mathrm{~g} \mathrm{Kg}^{-1}\right.$ of dry matter). The content of phytic acid in hemp varieties resulted inversely correlated with trypsin inhibitors and cyanogenic glycosides. Since the presence of phytic acid in meal may lead to mineral deficiencies over a long period of administration, the phytic acid contents in hempseed flour should be reduced to increase the safety of these flours, but avoiding altering trypsin inhibitor and cyanogenic glycoside contents.
\end{abstract}

Keywords: Cannabis sativa, Condensed Tannins, Cyanogenic Glycosides, Phytic Acid, Trypsin Inhibitors, Saponins

\section{Introduction}

Cannabis sativa L. has for centuries been a source of food and fiber [1-2]. Already in prehistoric times, hemp was used for human consumption and as a fiber in the manufacture of nets for hunting birds and small animals [2-3]. The oil obtained by pressing the seeds has been used as a medicine in China for at least 3,000 years [4]. Hempseed oil found also application in lubricants, detergents, paints and varnishes.

Hemp seed contains 320 to $380 \mathrm{~g} \mathrm{Kg}^{-1}$ oil [5], $80 \%$ of which is polyunsaturated fatty acids [6]. This oil is extremely rich in omega-6 and omega- 3 with an omega-6/omega-3 ratio around 2.5 [7], which is a value near that found in japanese and mediterranean diets, where the incidence of heart diseases has been historically low [8]. For this reason, hempseed oil is marketed as a health-promoting product [9]. There are various benefits attributed to omega-3 and include anti-cancer, anti-inflammatory and anti-thrombosis properties, stimulation of general metabolism and promotion of burning of fat [9-12].

To make the oil-extraction industry economically viable is necessary to find a market for the remaining meal. In the last century, the legal status of hemp in many nations has inhibited its use in animal feed. Hempseed meal is a rich source of protein and energy [7, 13]. Hempseed protein has good amounts of the sulphur-containing amino acids and very high levels of arginine and glutamic acid [7]. For its digestibility, hemp meal is equivalent to heat-treated canola meal [13]. Some examples are reported about feed made from hemp tested on animals [13-15]. However, little attention has been put so far on the presence of antinutritional factors in this flour.

Hemp meal may contain antinutritional components that need to be considered when feeding this product. The presence of condensed tannins, trypsin inhibitors, phytic acid and saponins in meal may lower the protein available either by precipitating it or inhibiting the digestive enzymes [16-20]. Phenomena of chelation or complex formation (phytic acid, condensed tannins, saponins) can reduce the absorption of mineral elements and vitamins [16,18,21]. The metabolism of some substances contained in flour may lead to the release of toxic products (i.e. cyanogenic glycosides to hydrogen cyanide)[22]. Moreover, saponins have pronounced haemolytic properties and are responsible for bloat 
in ruminants [20].

In the present study, the content of antinutritive compounds was evaluated in two groups of hemp varieties in order to better understand the limit of application of hemp meal as feed ingredient. The first group (Carmagnola, Carmagnola selezionata, Fibranova) was consisting of italian dioecious varieties and the second group (Fedora 17, Felina 32, Ferimon) of french monoecious varieties. The dioecious and monoecious hemp varieties have strong differences in the flowering time and seed filling [23].

\section{Materials and Methods}

\subsection{Plant material and Flour Preparation}

Seeds of 6 varieties of Cannabis sativa L. were used. Seeds of Carmagnola were obtained from Assocanapa (Italy). Carmagnola selezionata and Fibranova varieties were provided by Centro di Ricerca per le Colture Industriali CRA (Italy). Seeds of Fedora 17, Felina 32 and Ferimon were obtained from Cooperative Centrale des Producteurs de Semences de Chanvre (France). Seeds were ground in a mortar and mixed with hexane $(1: 10, \mathrm{w} / \mathrm{v})$. The solution was vigorously shaken for $30 \mathrm{~min}$. After centrifugation, the upper-liquid was collected and the extraction procedure repeated. The dried flour was used for analyses.

\subsection{Extraction and Separation of Phytic Acid}

Phytic acid was isolated from the meal using a modified method by deBoland et al. [24]. The phosphorus content of the precipitate was determined according to Russo and Reggiani [19]. Phytic acid was calculated by multiplying phytic acid phosphorus values by 3.55 [25].

\subsection{Extraction and Separation of Condensed Tannins}

The determination of condensed tannins was carried out as described by Butler et al. [26]. Condensed tannins were determined by the vanillin method (absorbance at $500 \mathrm{~nm}$ ) using catechin as a standard.

\subsection{Extraction and Assay of Trypsin Inhibitors}

Trypsin inhibitors was extracted from defatted flour with $2 \mathrm{mM}$ glycine buffer $\mathrm{pH} 11$ containing $2 \mathrm{mM} \mathrm{NaCl}, 10 \mathrm{mM}$ urea and $25 \mathrm{mM}$ EDTA. Trypsin inhibitor activity was measured according to Russo and Reggiani [27]. Activity of trypsin was measured by the absorbance at $410 \mathrm{~nm}$ due to p-nitroaniline released. One unit of trypsin inhibitor was defined as 0.01 decreases in absorbance at $410 \mathrm{~nm}$ under assay conditions compared with the control (without inhibitor).

\subsection{Extraction and Assay of Cyanogenic Glycosides}

Cyanogenic glycosides were extracted from defatted flour with $80 \%$ ethanol at $70^{\circ} \mathrm{C}$ twice. The samples were evaporated to dryness and then resuspended in water:n-butanol $(50: 50, v / v)$. After $1 \mathrm{~h}$ of agitation, the samples were cen- trifuged and the lower water layer recovered. Cyanogenic glycosides were assayed on the water extracts according to Russo and Reggiani [27].

\subsection{Extraction and Assay of Saponins}

Saponins were extracted from defatted flour with absolute methanol overnight in ration of dry weight of the sample to methanol as 1:20. The samples were centrifuged and the methanol extract evaporated to dryness and then resuspended in water:n-butanol $(1: 2, \mathrm{v} / \mathrm{v})$. After $1 \mathrm{~h}$ of agitation, the samples were centrifuged and the higher alcoholic layer recovered. Saponins were assayed according to Goel et al. [28] using Quillaja saponin as a reference standard [29].

\subsection{Statistical Analysis}

All statistical analysis were performed by SPSS version 16.0 software. Analysis of Variance (ANOVA) was applied to establish significant differences $(\mathrm{P}<0.01)$ between hemp varieties and groups in the level of antinutritive compounds. Mean separation was performed using Duncan's test and referring to $\mathrm{P} \leq 0.05$ probability level. Pearson's correlations between antinutritive compounds were also calculated.

\section{Results and Discussion}

In Table 1 is shown ANOVA for phytic acid, condensed tannins, trypsin inhibitors and cyanogenic glycosides for six varieties of hemp. ANOVA showed that are present highly significant variations $(\mathrm{P}<0.01)$ among varieties for all the antinutritives considered.

Table 1. Mean square and $F$ value from Analysis of Variance (ANOVA) for antinutritive compounds in flours of six varieties of Cannabis sativa

\begin{tabular}{cccc}
\hline Chemical Compound & d.f. $^{\text {a }}$ & Mean Square & F Value \\
\hline Phytic Acid & 5 & 63.70 & $16.70^{* * \mathrm{~b}}$ \\
Condensed Tannins & 5 & 0.280 & $27.14^{* *}$ \\
Trypsin Inhibitors & 5 & 105.96 & $69.00^{* *}$ \\
Cyanogenic Glycosides & 5 & 0.017 & $222.59^{* *}$ \\
Saponins & 5 & 161.63 & $27.66^{* *}$ \\
\hline
\end{tabular}

${ }^{a}$ d.f.: Degrees of freedom; ${ }^{b * *}$ : Significant at $\mathrm{P} \leq 0.01$

In Table 2 are shown the levels of antinutritive compounds for six hemp varieties divided into the two groups of belonging (italian and french). Of each group is shown the mean $\pm \mathrm{SE}$ and the significance of variability between groups $(\mathrm{P})$ is also reported.

As can be seen, the mean content of phytic acid ranged from 61.2 to $74.1 \mathrm{~g} \mathrm{Kg}^{-1}$ dry matter, with the varieties Felina 32 and Ferimon exhibiting the lowest level of phytic acid (letter "a" by the the Duncan's range test). Significant differences between groups were put in evidence, with the 
french group showing a lower mean content $\left(-0.55 \mathrm{~g} \mathrm{Kg}^{-1}\right.$ of dry matter). A content between $6-7 \%$ of phytic acid as observed in hemp flour is extremely high when compared to that of soy $(2 \%)$, which is the main ingredient used in animal diets [30].

As shown in Table 2, the content of condensed tannins varied from 1.36 to $2.14 \mathrm{~g} \mathrm{Kg}^{-1}$ of defatted flour. The mean level of condensed tannins resulted no significantly different between groups. These levels are no toxic (attention threshold is $1 \%$ of dry weight) and not so high as to reduce the palatability of the flours [31].

The variation in trypsin inhibitor activity in different hemp varieties was quite high. In Table 2 , the activity varied from 10.8 to 28.4 unit $\mathrm{mg}^{-1}$ of defatted flour. Fibranova exhibited trypsin inhibitor activity much lower than other varieties (letter "a" by the the Duncan's range test). The two groups resulted statistically different even though there was great variability within groups. These activities resulted similar to that observed in flax [27], but lower than those observed in some cereals or legumes [19,32].

Table 2. Antinutritive compounds in flours of italian (Carmagnola, CS, Fibranova) and french (Fedora 17, Felina 32, Ferimon) varieties of Cannabis sativa

\begin{tabular}{|c|c|c|c|c|c|}
\hline & Phytic Acid* & Condensed Tannins* & Trypsin Inhibitors** & Cyanogenic Glycosides* & Saponins $* * *$ \\
\hline Carmagnola & $64.9(\mathrm{bc})$ & 1.50 (a) & $22.2(\mathrm{c})$ & 0.11 (b) & 69.9 (b) \\
\hline Carmagnola selezionata & $66.0(\mathrm{c})$ & $1.36(\mathrm{a})$ & $21.5(\mathrm{c})$ & 0.09 (b) & 69.8 (b) \\
\hline Fibranova & $74.1(\mathrm{~d})$ & $1.85(b)$ & 10.8 (a) & 0.06 (a) & 69.1 (b) \\
\hline Mean+SE & $68.4 \pm 3.6$ & $1.57 \pm 0.18$ & $18.2 \pm 4.5$ & $0.09 \pm 0.02$ & $69.6 \pm 0.3$ \\
\hline Fedora 17 & $65.7(\mathrm{c})$ & $2.14(\mathrm{c})$ & 19.1 (b) & $0.22(\mathrm{c})$ & $65.8(b)$ \\
\hline Felina 32 & $61.9(\mathrm{ab})$ & 1.38 (a) & $24.6(d)$ & $0.24(\mathrm{~d})$ & 58.5 (a) \\
\hline Ferimon & $61.2(a)$ & $1.72(b)$ & $28.4(\mathrm{e})$ & $0.22(\mathrm{c})$ & $81.2(\mathrm{c})$ \\
\hline Mean+SE & $62.9 \pm 1.7$ & $1.75 \pm 0.27$ & $24.0 \pm 3.3$ & $0.23 \pm 0.01$ & $68.5 \pm 8.2$ \\
\hline $\mathrm{P}$ groups & 0.008 & ns & 0.023 & $<0.001$ & $\mathrm{~ns}$ \\
\hline
\end{tabular}

*data expressed as $\mathrm{g} \mathrm{Kg}^{-1} ; * *$ data expressed as unit $\mathrm{mg}^{-1} ;{ }^{* * *}$ data expressed as $\mathrm{mg} \mathrm{Kg}^{-1}$; Means with different letters in parentheses within the same column differ significantly by Duncan's range test $(\mathrm{P} \leq 0.05)$.

As can be seen, the mean content of cyanogenic glycosides was significantly different between italian and french varieties (Table 2). French varieties showed a content more than twice the italian varieties $\left(0.23\right.$ and $0.09 \mathrm{~g} \mathrm{Kg}^{-1}$, respectively). At levels above $100 \mathrm{ppm}$, the cyanogenic glycosides are harmful to health [33-34]. It follows that the italian varieties present acceptable levels of cyanogenic glycosides while those observed in french varieties (230 ppm) must be diluted to be considered safety.

The mean content of saponins was around $69.0 \mathrm{mg} \mathrm{Kg}^{-1}$ dry matter (Table 2), with the variety Ferimon exhibiting a level of saponins much higher than the others (letter "c" by the the Duncan's range test). No significant differences between groups were observed. A content of saponins as here observed in hemp flour result lower than that of soy and other plants [35-38].

In Table 3 is shown the correlation matrix calculated for the different antinutritional compounds. In this table, Pearson correlation coefficients are given as a measure of linearity between two class of compounds. From Table 3, it becomes clear that phytic acid is highly inversely correlated $(\mathrm{P}<0.0 .1)$ with cyanogenic glycosides and trypsin inhibitors, while these last two antinutritives are positively correlated between them. On the contrary, condensed tannins and saponins appeared not correlated with any other.

A renewed interest in hemp oil for the nutraceutical and various industries (lubricants, detergents, paints and varnishes), makes the remaining meal available for use as animal feed. Hempseed meal was successfully administered up to $20 \%$ of the diet with no apparent problems in ruminants, poultry, and aquaculture [13-15]. However, Gakhar et al. [39] reported a reduction in body weight of hen after 4 weeks of $20 \%$ hemp diet.

The use of hemp flour at $20 \%$ in feed allows to lower the concentration of cyanogenic glucosides to acceptable levels even for the french varieties. Instead, phytic acid should be watched carefully for its concentration in hempseed meal (Table 2). Even $20 \%$ of hemp flour in mixing with other flours (cereals, soy), these last having an average phytic acid content of $2 \%$, would lead to a feed at $2.8-3.0 \%$ of phytic acid (the highest value is related to the italian varieties). Although experiments using hempseed meal in animal diets are reported [13-15], over the long term should be checked whether the administration of this flour does not cause mineral deficiencies, especially for iron and zinc [40-41]. 
Table 3. Pearson correlation coefficients (r) among antinutritive compounds in six varieties of Cannabis sativa

\begin{tabular}{cccccc}
\hline & Phytic Acid & Condensed Tannins & Trypsin Inhibitors & Cyanogenic Glycosides & Saponins \\
\hline Phytic Acid & 1 & & & & \\
Condensed Tannins & 0.352 & 1 & & & \\
Trypsin Inhibitors & $-0.920^{*}$ & -0.395 & $0.661^{*}$ & 1 & 1 \\
Cyanogenic Glycosides & $-0.729^{*}$ & 0.122 & 0.234 & -0.172 & 1 \\
Saponins & -0.063 & 0.174 & & & \\
\hline
\end{tabular}

*Correlation is significant at the 0.01 level

To increase the safety of hempseed meal for animal feed would be desirable to reduce the content of phytate. The french varieties presented less phytic acid than those italian $\left(-0.55 \mathrm{~g} \mathrm{Kg}^{-1}\right.$, Table 2). Despite this, it is preferable that, through breeding, the phytic acid content in flour to be lowered to at least $4.5 \mathrm{~g} \mathrm{Kg}^{-1}$. Otherwise more research has to be pursued to identifying mutants with low-phytic acid as occurred in other species [42-43]. However, it is to be determined whether a decrease in the content of phytate would lead to an increase in the content of trypsin inhibitors and cyanogenic glycosides as expected by the inverse correlation here observed (Table 3).

\section{Acknowledgements}

The authors thank Regione Lombardia for financial support through project "VeLiCa" (no. 14840/RCC).

\section{References}

[1] Xiaozhai L. and Clarke R.C. 1995. The cultivation and use of hemp (Cannabis sativa L.) in ancient China. J Int Hemp Assoc 2: 26-33.

[2] Pringle H., 1997. Ice age community may be earliest known net hunters. Science 277: 1203-1204.

[3] McPartland M.J. and Geoffrey G.. "Random queries concerning the evolution of Cannabis and coevolution with the cannabinoid receptor", In: The Medicinal Use of Cannabis, G. Guy, R. Robson, K. Strong and B. Whittle, Eds. London: Royal Society of Pharmacists, 2004, pp. 71-102.

[4] de Padua L.S., Bunyaprafatsara N. and Lemmens R.H.M.J. (Eds.), 1999. Plant Resources of South-East Asia: Medicinal and Poisonous Plants, Vol. 1, No. 12, pp. 167-175. Backhuys Publishers, Leiden.

[5] Hullar I., Meleg I., Fekete S. and Romvari R., 1999. Studies on the energy content of pigeon feeds. 1.Determination of digestibility and metabolizable energy content. Poultry Sci. 78: $1757-1762$.

[6] Deferne J.L. and Pate D.W., 1996. Hemp seed oil: A source of valuable essential fatty acids. J Int Hemp Assoc 3: 1-7.
[7] Callaway J.C., 2004. Hempseed as a nutritional resource: an overview. Euphytica 140: 65-72.

[8] Simopoulos, A.P., Leaf A. and Salem N., 2000. Workshop statement on the essentiality of and recommended dietary intakes from omega- 6 and omega- 3 fatty acids. Prostaglandins Leukot Essent Fatty Acids 63: 119-121.

[9] Erasmus U., 1993. Fats that Heal, Fats that Kill. Alive Books. Burnaby, British Columbia, Canada.

[10] Simopoulos A.P., "Fatty acids", in Functional Foods: Designer Foods, Pharmafoods, Nutraceuticals, I. Goldberg, ed. New York: Chapman \& Hall, 1994, pp. 355-392.

[11] Leizer C., Ribnicky D., Poulev A., Dushenkov S. and Raskin I, 2000. The composition of hemp seed oil and its potential as an important source of nutrition. J Nutraceut, Functional \& Med Foods 2: 35-53.

[12] Lewis N.M., Seburg S. and Flanagan N.L., 2000. Enriched eggs as a source of N-3 polyunsaturated fatty acids for humans. Poultry Sci 79: 971-974.

[13] Mustafà A.F., Mckinnon J.J. and Christensen D.A., 1999. The nutritive value of hemp meal for ruminants. Can J Animal Sci 79: 91-95.

[14] Webster C.D., Thompson K.R., Morgan A.M., Grisby E.J. and Gannam A.L., 2000. Use of hempseed meal, poltry by-product meal, and canola meal in practical diets without fish meal for sunshine bass (Morone chrysops x M. saxatilis). Aquaculture 188: 299-309.

[15] Silversides F.G. and Lefrançois M.R., 2005. The effect of feeding hemp seed meal to laying hens. Br Poultry Sci 46: 231-235.

[16] Urbano G., López-Jurado M., Aranda P., Vidal-Valverde C., Tenorio E. and Porres J., 2000. The role of phytic acid in legumes: antinutrient or beneficial function? J Physiol Biochem 56: 283-294.

[17] Guillamón E., Pedrosa M.M., Burbano C., Cuadrado C., de Cortes Sánchez M., Muzquiz M., 2008. The trypsin inhibitors present in seed of different grain legume species and cultivar. Food Chem 107: 68-74. 
[18] Schlemmer U., Frǿlich W., Prieto R.M. and Grases F., 2009. Phytate in Foods and Significance for humans: Food Sources, Intake, Processing, Bioavailability, Protective Role and Analysis. Mol Nutr Food Res 53: 330-375.

[19] Russo R. and Reggiani R., 2012. Antinutritive compounds in twelve Camelina sativa genotypes. Am J Plant Sci 3: 1408-1412.

[20] Cheeke P.R., 1971. Nutritional and physiological implications of saponins: a review. Can J Anim Sci 51: 621-632.

[21] Amarowicz R., Estrella I., Hernández T., Robredo S., Troszynska A., Kosinska A. and Pegg R.B., 2010. Free Radical-Scavenging Capacity, Antioxidant Activity, and Phenolic Composition of Green Lentil (Lens culinaris). Food Chem 121: 705-711.

[22] Newkirk R., 2009. Flax feed industry guide. Winnipeg, Manitoba: Flax Canada 2015;. Available from: http://cigi.ca/wp-content/uploads/2011/12/2009_Flax-Feed-I ndustry-Guide.pdf

[23] Amaducci S., Colauzzi M., Zatta A. and Venturi G, 2008. Flowering dynamics in monoecious and dioecious hemp genotypes. J Ind Hemp 13: 5-19.

[24] deBoland A.R., Garner G.B. and O’Dell B.L., 1975. Identification and Properties of Phytate in Cereal Grains and Oilseed Products. J Agric Food Chem 23: 1186-1189.

[25] Raboy V. and Dickinson D.B., 1984. Effect of Phosphorus and Zinc Nutrition on Soybean Seed Phytic Acid and Zinc. Plant Physiol 75: 1094- 1098.

[26] Butler E.J., Pearson A.W. and Fenwick G.R., 1982. Problems Which Limit the Use of Rapeseed Meal as a Protein Source in Poultry Diets. J Sci Food Agric 33: 866- 875.

[27] Russo R. and Reggiani R., 2013. Variability of antinutritive compounds in twelve flaxseed flour. Int J Plant Biol, in press.

[28] Goel N., Sirohi S.K. and Dwivedi J., 2012. Estimation of total saponins and evaluate their effect on in vivo methanogenesis and rumen fermentation pattern in wheat straw based diet. J Adv Vet Res 2: 120-126.

[29] Shiau I.L., Shih T.L., Wang Y.N., Chen H.T., Lan H.F., Lin H.C., Yang B.Y., Ko C.H. and Murase Y., 2009. Quantification for saponin from a soapberry in cleaning products by a chromatographic and two colorimetric assays. J Fac Agric Kyushu University 54: 215-221.

[30] Kwanyuen P. and Burton J.W., 2005. A Simple and Rapid Procedure for Phytate Determination in Soybeans and Soy Products. J Am Oil Chem Soc 82: 81-85.

[31] Singleton V.L., 1981. Naturally Occurring Food Toxicants:
Phenolic Substances of Plant Origin Common in Foods. Adv Food Res 27: 149-242.

[32] Sosulski F.W., Minja L.A. and Christensen D.A., 1988. Trypsin inhibitors and nutritive value in cereals. Plant Food Hum Nutr 38: 23-34.

[33] Cardoso A.P., Ernesto M., Cliff J., Egan S.V. and Bradbury J.H., 1998. Cyanogenic potential of cassava flour: field trial in Mozambique of a simple kit. Int J Food Sci Nutr 49: 93-99.

[34] Ernesto M., Cardoso P., Nicala D., Mirione E., Massaza F. and Cliff J., 2002. Endemic konzo and cyanide toxicity from cassava in Northern Mozambique. Acta Tropica 82: 357-362.

[35] Tsukamoto C., Shimada S., Igita K., Kudou S., Kokubun M., Okubo K. and Kitamura K., 1995. Factor affecting isoflavone content in soybean seeds: changes in isoflavones, saponins, and composition of fatty acids at different temperatures during seed development. J Agric Food Chem 43: 1184-1192.

[36] Oakenfull D., 1981. Saponins in food - A review. Food chem. 6: $19-40$.

[37] Price K.R., Curl C.R. and Fenwick G.R., 1986. The saponin content and sapogenol composition of the seed of 13 varieties of legume. J Sci Food Agric 37: 1185-1191.

[38] Reichert R.D., Tatarinovich J.T. and Tyler R.T., 1986. Abrasive dehulling of Quinoa (chenopodium quinoa): Effect of saponin content as determined by an adapted haemolytic assay. Cereal Chem 63: 471-475.

[39] Davies N.T. and Nightingale R., 1975. The effect of phytate on intestinal absorption and secretion of zinc, and whole-body retention of $\mathrm{Zn}$, copper, iron and manganese in rats. Br J Nutr 34: 243-257.

[40] Gakhar N., Goldberg E., Jing M., Gibson R. and House J.D., 2012. Effect of feeding hemp seed and hemp seed oil on laying hen performance and egg yolk fatty acid content: evidence of their safety and efficacy for laying hen diets. Poultry Sci 91: 701-711

[41] Reddy M.B. and Cook J.D., 1991. Assessment of dietary determinants of nonheme-iron absorption in humans and rats. Am J Clin Nutr 54: 723-728.

[42] Raboy V., Gerbasi P.F., Young K.A., Stoneberg S.D., Pickett S.G., Bauman A.T., Murthy P.P., Sheridan W.F. and Ertl D.S., 2000. Origin and seed phenotype of maize low phytic acid 1-1 and low phytic acid 2-1. Plant Physiol 124: 355-368.

[43] Wilcox J.R., Premachandra G.S., Young K.A. and Raboy V., 2000. Isolation of high seed inorganic $P$, low phytate soybean mutants. Crop Sci 40: 1601-1605. 